\title{
Magnitude of postpartum depression and associated factors among women in Mizan Aman town, Bench Maji zone, Southwest Ethiopia
}

Tigistu Toru $^{1 *}$, Fantaye Chemir ${ }^{2+}$ and Susan Anand ${ }^{2+}$

\begin{abstract}
Background: The first 12 months after childbirth may represent a high-risk time for depression. In Ethiopia there is a paucity of evidence about its magnitude and associated factors during that period. So, the aim of this study was to assess the magnitude of depression and associated factors among postpartum women in Mizan Aman town, Bench Maji Zone, Southwest Ethiopia 2017.

Methods: A community based cross- sectional study design was employed from March 15 to April 15, 2017. Four hundred sixty women were selected using multistage random sampling technique. Face to face interview were conducted using structured questionnaires and standardized scales. Bivariate logistic regression analysis was done to see crude association between each independent variable and outcome variable. Variables with $p$ value $<0.25$ in bivariate analysis were entered to multivariable logistic regression analysis to control for confounding. Adjusted odd ratios with $95 \% \mathrm{Cl}$ were calculated to identify independent predictors of postpartum depression.

Result: Four hundred fifty-six postpartum women participated in the study giving a response rate of 99\%. The magnitude of postpartum depression among the study population was 102 (22.4\%, 95\% Cl: 19.84-24.96).

Postpartum depression is relatively higher in the first 6 weeks after birth. Postpartum depression is higher among mothers with age range between 18 and 23 years (aOR 3.89 95\% Cl: 1.53-9.90), unplanned pregnancy (aOR 3.35 95\% Cl: 1.701-6.58), child having sleeping problems (aOR 3.72 95\%Cl: 1.79-7.72), domestic violence (aOR 2.86 95\%Cl 1.72-8.79), unsatisfied marital relation (aOR 2.72 95\% Cl 1.32-5.62), poor social support (aOR $4.3095 \% \mathrm{Cl} 1.79-10.30$ ), history of previous depression (aOR $7.3895 \% \mathrm{Cl} 3.12-17.35$ ) and substance use (aOR $5.1695 \% \mathrm{Cl} 2.52-10.60$ ).
\end{abstract}

Conclusion: The magnitude of postpartum depression was high. This underlines health care planners' needs to incorporate screening strategies for depression following childbirth.

Keywords: Postnatal, Depression, Magnitude, Mental health, Ethiopia

\section{Background}

Depression is a significant contributor to the global burden of disease and affects people in all communities across the world [1]. Major depressive disorder is among the top ten causes of years lived with disability (YLDs) in every country [2].

\footnotetext{
* Correspondence: tigistutoru112@gmail.com

${ }^{\dagger}$ Fantaye Chemir and Susan Anand contributed equally to this work.

${ }^{1}$ Mizan Aman college of health science, Mizan Aman, Ethiopia

Full list of author information is available at the end of the article
}

The postpartum period is well established as an increased time of risk for the development of serious mood disorders [3]. Postpartum depression can be defined as a non-psychotic depression that happens during the first 12 months after childbirth. The symptoms are no different from depression which anyone can have [4]. It is a type of depression that affects about one in 10 new mothers within the first year after childbirth and has the potential to negatively impact a new mother's health and her ability to nurture her infant [5].

(c) The Author(s). 2018 Open Access This article is distributed under the terms of the Creative Commons Attribution 4.0 International License (http://creativecommons.org/licenses/by/4.0/), which permits unrestricted use, distribution, and reproduction in any medium, provided you give appropriate credit to the original author(s) and the source, provide a link to the Creative Commons license, and indicate if changes were made. The Creative Commons Public Domain Dedication waiver (http://creativecommons.org/publicdomain/zero/1.0/) applies to the data made available in this article, unless otherwise stated. 
The prevalence of postpartum depression in African American women ranges from 10 to 15\% [6].

A synthesis of evidence in a systematic review on common perinatal mental disorders in women in low and middle income countries revealed a pooled prevalence of postpartum common mental disorders to be higher than in high-income countries with an average prevalence rate of $19.8 \%$. However, perinatal mental health of women living in low and middle income countries has only recently become the subject of research since the priority is given to preventing pregnancy related complications [7].

Despite the fact that postpartum depression is the major maternal mental health problem following childbirth, little was known about the magnitude of the problem and contributing factors in Ethiopia in general and it was not investigated in the study area in particular; therefore, this study was aimed to fill this gap.

\section{Methods}

\section{Study area and period}

This study was conducted in Mizan-Aman town from March 152017 to April 15 2017. Mizan Aman is Bench Maji zonal town, one of the 13th zones in the Southern Nations Nationalities and People's Regional Government (SNNPRG). The town is located $561 \mathrm{Km}$ away from Addis Ababa and $832 \mathrm{Km}$ away from Hawassa (capital of SNNPRG). Mizan Aman Town is administratively structured by five kebeles and has an estimated total population of 50,113 of which 23,721 were females. Out of all females, 11,679 were women of reproductive age (1549 yr.). The town has one teaching hospital, one health center and five health posts and all are runned by the government. On the other hand, there were nine private clinics and eight drug stores.

\section{Study design}

Community based quantitative cross-sectional study.

\section{Source and study population}

The source populations for the study were all postpartum women who gave birth within 12 months before data collection. Randomly selected women who gave birth within 12 months prior to data collection and who fulfilled the eligibility criteria were included. Women who gave birth within the last 12 months prior to data collection irrespective of type of delivery and outcome of delivery were included in the study.

\section{Sampling procedure}

Sample size was determined by using single population proportion formula based on the assumptions of 19\% proportion of women who developed postpartum depression from a previous study in Tigray region,
Northern part of Ethiopia [8] with precision (margin of error) $5 \%$ between sample and population parameter and $95 \%$ confidence level. The final sample of 460 postpartum women was included in the study after considering finite population correction, design effect of two and $10 \%$ non-response rate.

Three among five kebeles in the town were selected using lottery method. Then, the sample was proportionally allocated to the three kebeles and simple random sampling technique was used to get 460 participants from 1720 postpartum mothers by taking the community health extension workers' postpartum registration book as a frame.

\section{Measurement}

An interviewer-administered structured questionnaire containing socio-demographic, obstetric, pediatric, psychosocial, substance use, psychiatric and medical illness history was adopted from previously published studies. Moreover, 9- items Patient Health Questionnaire, 3-item Kansas Marital Satisfaction Scale and 3-item Oslo Social Support Scale were used to assess the magnitude of postpartum depression, level of marital satisfaction and level of social support respectively (Additional file 1).

The questionnaire is prepared in English and then translated to local language (Amharic) as well as back to English by bilingual experts in order to check consistency. Pretest was done by taking $5 \%$ of the sample in 'Kometa' kebele which was not included in the actual data collection phase to assess the face validity of the questionnaire.

\section{Data collection}

Six trained diploma nurses collected the data while three BSc nurses closely supervised data collection procedures. The principal investigator followed the overall data collection procedure plan. Face to face interviewer administered method of data collection was employed using structured questionnaires. Actual data collection was conducted after minor modification was made on tools based on pre-test findings. To assure the quality of the data, data collectors and supervisors were trained for two days on the clarity of tools and overall data collection procedures to standardize interview procedures and reduce interviewers' bias.

\section{Data analysis}

Data was entered to Epi- Data version 3.1 and then exported to SPSS version 21 for analysis purpose. Before analysis, missing values were checked and new categories created as needed. Descriptive statistics (frequencies, percentages) were performed. Bivariate logistic regression analysis was employed to determine the crude association between the dependent variable with each independent 
variable. Those exposure variables with $p$-values $<0.25$ were entered into multivariable logistic regression analysis to control for confounders. Adjusted odds ratios with 95\% CI were used to identify statistically significant associations between dependent and independent variables.

\section{Operational and term definitions Postpartum depression}

In this study, postpartum depression was measured by using the Patient Health Questionnaire scale with 9 items and total sum score of 27. PD was categorized in to depressed (total sum score $\geq 10$ ) and not depressed (total sum score $<10$ ) [9].

\section{Infant sleeping problem}

Infants sleeping problem was defined based on maternal response of infants sleep duration as irregular or not sufficient.

\section{Baby blues}

Were measured by mother's experience of mood instability, depressed mood, sadness, irritability, anxiety, lack of concentration and/or feelings of dependency within two weeks following childbirth.

\section{Level of marital satisfaction}

Was assessed using Kansas Marital Satisfaction scale with 3 items and total sum score of 21 . Total sum score of 17 and above was used as a cutoff point to identify women satisfied with their marital relation. Total sum score below 17 indicates dissatisfaction with marital relation [10].

\section{Domestic violence}

Is any behavior within an intimate relationship that causes physical, psychological or sexual harm and reported by mothers with yes or no items. Mothers were categorized as a victim of domestic violence when they experienced any of the harms (physical, psychological and sexual) in their intimate relationship.

\section{Social support}

Measures of available support that women perceive or believe that people in their social network would provide in times of need. Measured by 3- Items Oslo Social Support Scale with total sum score of 15 and categorized as; a score of $3-8$ is poor support, $9-11$ is moderate support and $12-15$ is strong support [11].

\section{Women substance use history}

Is history of using any kind of substances such as fabricated or local alcohol, chat chewing, cigarette or tobacco smoking and other such addictive substance during pregnancy or after childbirth measured by yes or no items with at least one yes response.

\section{Husband substance use}

Husband's history of using any kind of substances such as fabricated or local alcohol, chat chewing, cigarette or tobacco smoking and other such addictive substance and measured by at least one yes response.

\section{Result}

From four hundred sixty women, 456 women completed the interview which gives a response rate of $99 \%$.

\section{Socio demographic characteristics of participants}

All the study participants age ranged from 18 years to 39 years with majority 192 (42.1\%) between 18 and 23 years. Four hundred forty-three (97.1\%) of women were married, 163 (35.7\%) were from Bench Ethnic group, 179 (39.3\%) participants followed Orthodox religion, and 211 (46.3\%) had attended up to diploma level and above. Regarding husband's educational level and occupation, 152 (34.3\%) had diploma and above and 229 (51.7\%) were merchants. One hundred fifty-three (33.6\%) participants reported that their average family monthly income from all sources was less than 1000 ETB ( 35 USD) (Table 1).

\section{Magnitude of postpartum depression}

According to this study, the maximum sum score which was recorded by participants was 16 . The overall prevalence of postpartum depression among the study participant was found to be 102 (22.4\%) (Fig. 1). Among those depressed, the prevalence of depression was more or less similar during the first six weeks 38 (37.3\%), during 6 weeks to 6 months 33(32.4\%) and above 6 months' postpartum period $31(30.4 \%)$.

\section{Factors associated with postpartum depression}

Among all the explanatory variables entered to bivariate binary logistic regression analysis, nineteen of them with $p$-value $<0.25$ entered into multivariable analysis to control for confounding. These variables include age, marital status, women' occupation, family monthly income, gravidity, status of recent pregnancy, complication after childbirth, difficulty of child feeding, child sleeping problem, domestic violence, marital satisfaction, social support level, previous depression, family mental illness, recent medical illness and substance use. Eight independent predictor variables for occurrence of postpartum depression were identified in the multivariable binary logistic regression model.

Accordingly, mothers prone to postpartum depression were likely to be those with; history of previous depression (aOR: 7.38, 95\%CI: 3.12-17.35), substance use (aOR: 5.17, 95\%CI: $2.52-10.60$ ), poor social support (aOR: $4.30,95 \% \mathrm{CI}$ : 1.79-10.30), age range between 18 and 23 years (aOR: 3.89, 95\%CI: 1.53-9.90), infant sleeping problems (aOR: 3.72, 95\%CI: 1.79-7.72), unplanned pregnancy (aOR: 3.35, 95\%CI: 1.70-6.58), domestic violence (aOR: 2.86 95\% CI 
Table 1 Socio-demographic characteristics of postpartum women in Mizan Aman Town, Bench Maji Zone, SNNPR, Ethiopia from March 15, 2017 to April 15, $2017(n=456)$

\begin{tabular}{|c|c|c|c|}
\hline Variables & Category & Frequency & Percentage \\
\hline \multirow[t]{3}{*}{ Age } & $18-23$ & 192 & 42.1 \\
\hline & $24-29$ & 167 & 36.6 \\
\hline & $>=30$ & 97 & 21.3 \\
\hline \multirow[t]{3}{*}{ Marital status } & Married & 443 & 97.1 \\
\hline & Others & 13 & 2.9 \\
\hline & \multicolumn{3}{|c|}{ Others: divorced, widowed, separated } \\
\hline \multirow[t]{7}{*}{ Ethnicity } & Bench & 163 & 35.7 \\
\hline & Amhara & 99 & 21.7 \\
\hline & Keffa & 79 & 17.3 \\
\hline & Oromo & 46 & 10.1 \\
\hline & Gurage & 24 & 5.3 \\
\hline & Tigre & 24 & 5.3 \\
\hline & Others & 21 & 4.3 \\
\hline \multirow[t]{4}{*}{ Religion } & Orthodox & 179 & 39.3 \\
\hline & Protestant & 162 & 35.5 \\
\hline & Muslim & 94 & 20.6 \\
\hline & Catholic & 21 & 4.6 \\
\hline \multirow[t]{4}{*}{ Women education } & $\begin{array}{l}\text { Unable to read and } \\
\text { write }\end{array}$ & 16 & 3.5 \\
\hline & Elementary & 147 & 32.2 \\
\hline & Secondary & 82 & 18.0 \\
\hline & Diploma and above & 211 & 46.3 \\
\hline \multirow[t]{5}{*}{ Women occupation } & $\begin{array}{l}\text { Government } \\
\text { employee }\end{array}$ & 199 & 43.6 \\
\hline & Housewife & 166 & 36.4 \\
\hline & Merchant & 61 & 13.4 \\
\hline & Private employee & 25 & 5.5 \\
\hline & Student & 5 & 1.1 \\
\hline \multirow[t]{4}{*}{ Husband education } & $\begin{array}{l}\text { Unable to read and } \\
\text { write }\end{array}$ & 33 & 7.4 \\
\hline & Elementary & 147 & 33.2 \\
\hline & Secondary & 111 & 25.1 \\
\hline & Diploma and above & 152 & 34.3 \\
\hline \multirow[t]{5}{*}{ Husband occupation } & Merchant & 229 & 51.7 \\
\hline & $\begin{array}{l}\text { Government } \\
\text { employee }\end{array}$ & 117 & 26.4 \\
\hline & Private employee & 75 & 16.9 \\
\hline & Others & 22 & 5 \\
\hline & \multicolumn{3}{|c|}{ Others: student, farmer, contractor, carpenter } \\
\hline \multirow{3}{*}{$\begin{array}{l}\text { Average family monthly } \\
\text { income }(E T B)^{a}\end{array}$} & $<1000$ & 153 & 33.6 \\
\hline & $1000-2000$ & 179 & 39.2 \\
\hline & $>2000$ & 124 & 27.2 \\
\hline
\end{tabular}

$\mathrm{a}_{1} \mathrm{USD}=\sim 28 \mathrm{ETB}$
1.72,8.79), and unsatisfied marital relation (aOR: 2.72, 95\%CI 1.32-5.62) (Table 2).

\section{Discussion}

The magnitude of postpartum depression in this study was $22.4 \%$ (95\% CI: 19.84-24.96). This was higher when compared with findings from Southern India (12\%) [12], Sudan (9.2\%) [13], Greenland (8.6\%) [14] and Northern part of Ethiopia (19\%) [8]. The variation might be due to differences in study setting (facility based in India), or measurement scale (Edinburgh depression screening tool in most of the studies). The higher postpartum depression prevalence in this study may also be explained by low living standards in the study setting where $3 / 4$ (72.8\%) of the mothers had low socio-economic status. This finding was in agreement with the findings from Sudan [13] and Egypt [15] where mothers with low household income were more likely to develop PPD.

The magnitude of postpartum depression in this study was found to be lower than findings from Egypt (49.5\%) [15], South Africa (50.3\%) [16] and Nigeria (28\%) [17]. The discrepancy might also be attributed to differences in sampling methods utilized since we used 12-month period while the comparable studies used less than 6 months which may make sample size smaller. Social desirability bias is most likely since we have employed interviewer administered method of data collection technique. This could have made them not feeling safe and therefore not willing to express their true feelings and ideas. The presence of a different measurement scale for measuring depression might also contribute to the discrepancy in the prevalence in both directions.

Postpartum depression was more common among women age between 18 and 23 years compared with thirty years and above. This might be due to younger women being more exposed to emotional distress as they experience childbirth for the first time and extra burden was added for caring infants as well as the whole family in this particular period. This finding is consistent with findings in Sudan and North America [13, 18].

Women who did not plan their pregnancy were nearly three times more likely to experience PPD when compared with their counter parts. This is in line with findings in South Africa [16] and Cameroon [19]. This might be explained as inadequate preparation for pregnancy, childbirth, and nursing, leading to mothers to feel anxious, helpless and have less (or no) ability to cope with all the changes and challenges babies bring.

Mothers whose infants had sleeping problems were nearly four times more likely to be depressed when compared with mothers whose infants sleep regularly. The findings are consistent with findings in Cameroon [19] and Egypt [15]. This could be explained as sleeping problems in the early years would cause maternal sleep 


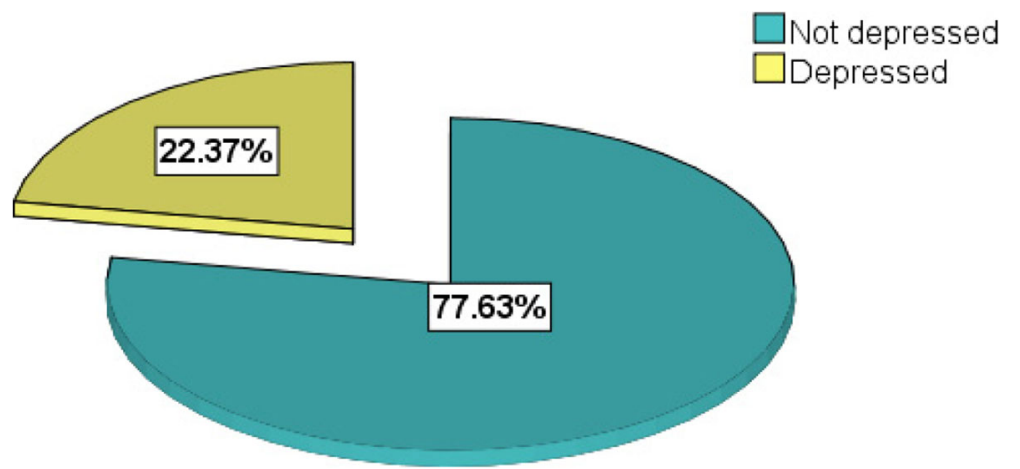

Fig. 1 Prevalence of postpartum depression among women in Mizan Aman Town, Bench Maji Zone, Southwest Ethiopia 2017

loss and feelings of fatigue contributing to maternal depressive symptoms. The current study also identified that the odds of postpartum depression among women who experienced domestic violence from their partner was nearly four times higher than those who did not. This is in line with findings in Egypt [15], Sudan [13] and Japan [20]. Violence of any kind has a devastating physical, psychological, behavioral and developmental effect on the victims.

The occurrence of postpartum depression was high among women who were previously diagnosed for depression. This is explained in studies conducted in China and Canada [21, 22]. Women with unsatisfied marital relations and poor social support were more likely to experience postpartum depression. This finding was supported by findings in Cameroon [19], Pakistan, Iran [23] and South Asia [24]. Lack of support, love, affection and guidance of husband on top of a stressful childbirth event could make women vulnerable to PPD. Women who have a history of substance use were nearly five times more likely to have postpartum depression than non-users. Similarly, this is supported by findings from a systematic review [25]. Postpartum substance use could limit a mother's ability to stay emotionally connected to

Table 2 Predictors of postpartum depression in multivariable analysis among postpartum women in Mizan Aman Town, Bench Maji Zone, Southwest Ethiopia March to April, 2017

\begin{tabular}{|c|c|c|c|c|}
\hline Variables & Category & Depressed N (\%) & Not depressed N (\%) & $\mathrm{aOR}(95 \% \mathrm{Cl})$ \\
\hline \multirow[t]{3}{*}{$\overline{\text { Age }}$} & $18-23$ & $71(37)$ & $121(63)$ & $3.89(1.5,9.9)^{\mathrm{a}}$ \\
\hline & $24-29$ & 19(11.4) & 148(88.6) & $0.72(0.2,2.1)$ \\
\hline & $>=30$ & $12(12.4)$ & 85 (87.6) & 1 \\
\hline \multirow[t]{2}{*}{ Recent pregnancy status } & Unplanned & $71(33)$ & $126(67)$ & $3.35(1.7,6.6)^{a}$ \\
\hline & Planned & $31(15)$ & $228(85)$ & 1 \\
\hline \multirow[t]{2}{*}{ Child sleeping problem } & Yes & $54(55)$ & $45(45)$ & $3.72(1.8,7.7)^{\mathrm{a}}$ \\
\hline & No & $48(13)$ & $309(87)$ & 1 \\
\hline \multirow[t]{2}{*}{ Domestic violence } & Yes & $40(42.5)$ & $54(57.5)$ & $2.86(1.7,8.8)^{\mathrm{a}}$ \\
\hline & No & $62(20)$ & 299(80) & 1 \\
\hline \multirow[t]{2}{*}{ Marital satisfaction } & Dissatisfied & $70(36.5)$ & $129(63.5)$ & $2.72(1.3,5.6)^{a}$ \\
\hline & Satisfied & $26(10)$ & $221(90)$ & 1 \\
\hline \multirow[t]{3}{*}{ Social support } & Poor & $53(54)$ & $41(46)$ & $4.29(1.8,10.3)^{a}$ \\
\hline & Moderate & $24(17)$ & $137(83)$ & $2.00(0.8,4.9)$ \\
\hline & Good & $25(12)$ & $176(88)$ & 1 \\
\hline \multirow[t]{2}{*}{ Previous depression } & Yes & $40(71)$ & $27(29)$ & $7.38(3.1,17.4)^{\mathrm{a}}$ \\
\hline & No & $62(12)$ & $327(88)$ & 1 \\
\hline \multirow[t]{2}{*}{ Substance use } & Yes & $52(49)$ & $57(51)$ & $5.16(2.5,10.5)^{a}$ \\
\hline & No & $50(12)$ & 297(88) & 1 \\
\hline
\end{tabular}

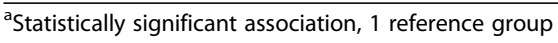


her infant, adjust to his or her rhythms and behaviors, and anticipate or follow his or her development.

\section{Strengths and limitations of the study}

The study used a community based design which helped to address those mothers who were unable to visit health care facilities enhancing generalizability of the findings. Standardized tools which were tested for their validity according to Ethiopian context were employed to diagnose depression. Women may commit social desirability bias in order to avoid discrimination that could follow after stating that they have mental health problems. The cross-sectional nature of the study limits the capacity to draw any causal implications.

\section{Conclusion}

The magnitude of postpartum depression among women in the study was significantly higher requiring better strategies to integrate maternal mental health care packages during prenatal and postpartum periods. The study also reported different factors that contribute to the occurrence of postpartum depression such as unplanned pregnancy, presence of domestic violence, unsatisfied marital relation, poor social support and substance use history. Increasing awareness and access to contraceptive options during the preconception period will enhance maternal pregnancy planning. Health institutions should devise a strategy to create and strengthen support groups that create opportunities for positive interpersonal exchanges and emotional support for the mothers during pregnancy and after childbirth. In the community, health extension workers could provide anticipatory guidance for new mothers, such as organizing peer-support group fora and facilitating vicarious experience, as it is recognized as a parental self-efficacy enhancement strategy.

\section{Additional file}

Additional file 1: Measurement tools for data collection. The section containing structured questionnaires and measurement scales used to assess the study variables. (DOCX $35 \mathrm{~kb}$ )

\section{Abbreviations}

aOR: Adjusted odds ratio; CMD: Common mental disorders; ICD10: International classification of diseases, 10th revision; IPV: Intimate partner violence; LICs: Low- income countries; PND: Postpartum depression; WHO: World Health Organization

\section{Acknowledgements}

We would like to acknowledge Jimma University for giving financial support to do this research. We also acknowledge the data collectors, supervisors and study participants.

\section{Funding}

This study was funded by Jimma University in partial fulfillment of the requirement for masters of Science degree in maternity health nursing.
Availability of data and materials

The datasets used and/or analyzed during the current study are available from the corresponding author on reasonable request.

\section{Authors' contributions}

TT involved in designing of the study, data collection, data analysis, drafting and critically reviewing the manuscript. FC and SA involved in designing of the study, analysis of the data and critically reviewing the manuscript. All authors read and approved the final manuscript.

\section{Authors' information}

$\Pi \mathrm{T}$ is lecturer of maternal health nursing in Mizan Aman College of Health Science; FC is lecturer of maternal health nursing in institute of health, Jimma University and SA is professor of psychiatry in institute of health, Jimma University. All authors are currently staff members in their respective school in aforementioned institutions.

\section{Ethics approval and consent to participate}

Ethical clearance was obtained from the Institution Review Board of Jimma University. The collaboration letter was submitted to the Bench Maji Zone Health department and permission was obtained to conduct study on specified area. The benefit and full right not to take part in the study as well right to withdraw during interview was clearly stated. Confidentiality was maintained by using anonymous questionnaire and privacy was assured during interview.

Data collectors asked Amharic version of questionnaires after obtaining informed verbal and written consent from each participant. Participants with moderate depression symptoms were told to visit health facilities in order to consult psychiatrists or other clinicians and those with moderately severe depression were referred to hospital for further evaluation by psychiatrists. Moreover, women who reported suicidal ideation were also referred in order to get continuous psychological treatment and professional counseling regarding their current mental distress.

\section{Consent for publication}

Consent for publication is not applicable since there are no details, images, or videos relating to an individual person in this study.

\section{Competing interests}

The authors declare that they have no competing interests.

\section{Publisher's Note}

Springer Nature remains neutral with regard to jurisdictional claims in published maps and institutional affiliations.

\section{Author details}

${ }^{1}$ Mizan Aman college of health science, Mizan Aman, Ethiopia. ${ }^{2}$ School of nursing and midwifery, Jimma University, Jimma, Ethiopia.

Received: 16 October 2017 Accepted: 23 October 2018

Published online: 14 November 2018

\section{References}

1. World Health Organization. Depression- a global public health concern. 2012. http://www.who.int/mental_health/management/depression/who_ paper_depression_wfmh_2012.pdf. Accessed 15 Oct 2016.

2. Global Burden of Disease Study. Global, regional, and national incidence, prevalence, and years lived with disability for 301 acute and chronic diseases and injuries in 188 countries, 1990-2013: a systematic analysis for the Global Burden of Disease Study 2013. Lancet. 2015;386:743-800.

3. Stewart, D.E., Robertson, E., Dennis, C-L., Grace, S.L., \& Wallington, T. Postpartum depression: literature review of risk factors and interventions 2003 http://www.who.int/mental_health/prevention/suicide/lit_review_ postpartum depression.pdf. Accessed 20 Jan 2017.

4. Guille CN, Fryml R, et al. Management of postpartum depression. J Midwif Women's Health. 2013:58:643-53 (PUBMED).

5. Oklahoma State Department of Health. Recognizing Postpartum Depression. Oklahoma City; 2011. https://www.ok.gov/health2/documents/ PPDepression\%205.23.11.pdf. Accessed 22 Oct 2016.

6. Moses-Kolko E, Roth EK. Antepartum and postpartum depression: healthy mom, healthy baby. J Am Med Wom Assoc. 2004;59:181-91 (PUBMED). 
7. Fisher JRW, et al. Prevalence and determinants of common perinatal mental disorders in women in low- and lower-middle-income countries: a systematic review. Bull World Health Organ. 2012;90:139-49.

8. Mersha AG, Abebe SA, Sori LM, Abegaz TM. Prevalence and associated factors of perinatal depression in Ethiopia: a systematic review and metaanalysis. Depress Res Treat. 2018;2018:8 Article ID 1813834, (PUBMED).

9. Gelaye, et al. Validity of the patient health Questionnaire-9 for depression screening and diagnosis in East Africa. Psychiatry Res. 2013;210:653-61 (PUBMED).

10. Crane D, Middleton C, Kenneth A, Bean R. Establishing criterion scores for the Kansas marital satisfaction scale (KMSS) and the revised dyadic adjustment scale (RDAS). Am J Fam Ther. 2000;28:53-60 (Cross Ref).

11. Bøen, et al. The importance of social support in the associations between psychological distress and somatic health problems and socio-economic factors among older adults living at home: a cross sectional study. BMC Geriatr. 2012:12:27 (PUBMED).

12. Hirani D, Bala DV. A study of postnatal depression and its determinants in postnatal women residing in rural areas of Ahemdabad district, Gujarat, India. IOSR-JDMS. 2015;14(7):10-5 http://www.iosrjournals.org/iosr-jdms/ papers/Nol14-issue7/Nersion-7/C014771015.pdf.

13. Khalifa et al. Postnatal depression among Sudanese women: prevalence and validation of the Edinburgh postnatal depression scale at 3 months postpartum Int J Women's Health 2015; 7: 677-84. (PUBMED).

14. Iben Motzfeldt, et al. Prevalence of postpartum depression in Nuuk, Greenland- a cross sectional study using Edinburgh postnatal depression scale. Int J Circumpolar Health. 2013;72:21114 (PUBMED).

15. Mohammed ES, et al. Predictors of postpartum depression among rural women in Minia, Egypt: an epidemiological study. Public Health. 2014; 128(9):817-24 https://doi.org/10.1016/j.puhe.2014.06.006.

16. Stoltenberg EL, Abrahams JM. Prevalence of and factors influencing postnatal depression in a rural community in South Africa. Afr J Prm Health Care Fam Med. 2015;7(1) (PUBMED).

17. Danasabe M, Elias Bt N. Postpartum depression among Hausa ethnic women in Abubakar Tafawa Balewa University teaching hospital, north East Nigeria. IMPACT: international journal of research in humanities. Arts Literat (IMPACT: IJRHAL). 2016;4(3):55-64 http://oaji.net/articles/2016/488-1460366334.pdf. Accessed 1 Apr 2017

18. Brett K, Barfield W, Williams C. Prevalence of self-reported postpartum depressive symptoms (2004-2005). MMWR. 2008;57(14):361-6 https://www. cdc.gov/mmwR/preview/mmwrhtml/mm5714a1.htm. Accessed 3 Nov 2016.

19. Adama, et al. Prevalence and risk factors of postpartum depression in Yaounde, Cameroon. Open J Obst Gynecol. 2015;5:608-17 http://file.scirp. org/Html/6-1431004_59760.htm. Accessed 15 Sept 2016.

20. Miura A, Fujiwara T. Intimate partner violence during pregnancy and postpartum depression in Japan: a cross-sectional study. Front Public Health. 2017;5:81 (PUBMED).

21. Chi, et al. Screening for postpartum depression and associated factors among women in China. Front Psychol. 2016;7:3-8 (PUBMED).

22. Lanes, et al. Prevalence and characteristics of Postpartum Depression symptomatology among Canadian women. BMC Public Health. 2011; (PUBMED).

23. Jahromi MK, et al. A study of marital satisfaction among non-depressed and depressed mothers after childbirth in Jahrom, Iran. Global J Health Sci. 2015; 7(3):140 (PUBMED).

24. Abdollahi F, Lye MS, Md Zain A, Shariff Ghazali S, Zarghami M. Postnatal depression and its associated factors in women from different cultures. Iran J Psychiatry Behav Sci. 2011:5(2):5-11 (PUBMED).

25. Ross $L$, Dennis $C$. The prevalence of postpartum depression among women with substance use, an abuse history, or chronic illness: a systematic review. J Women's Health. 2009;18(4):1-13 (PUBMED).

\section{Ready to submit your research? Choose BMC and benefit from:}

- fast, convenient online submission

- thorough peer review by experienced researchers in your field

- rapid publication on acceptance

- support for research data, including large and complex data types

- gold Open Access which fosters wider collaboration and increased citations

- maximum visibility for your research: over $100 \mathrm{M}$ website views per year

At BMC, research is always in progress.

Learn more biomedcentral.com/submissions 